\title{
[2+3]-Cycloaddition Route to Pyrazole Boronic Esters from Sydnones and Alkynylboronates
}

Key words

cycloaddition

$\mathrm{N}$-aryl sydnones

pyrazole boronic esters

alkynylboronates
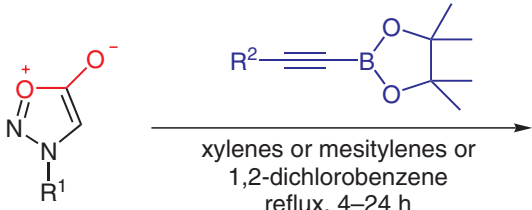

reflux, 4-24 h
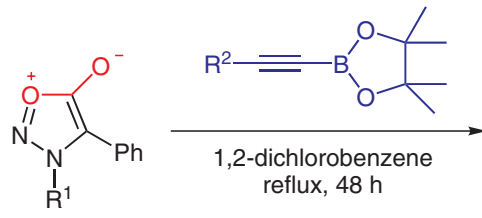

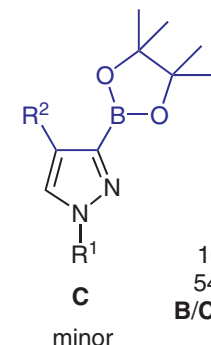

10 examples
$54-83 \%$ yield
$\mathbf{B} / \mathbf{C}>98: 2$ to $1: 7$

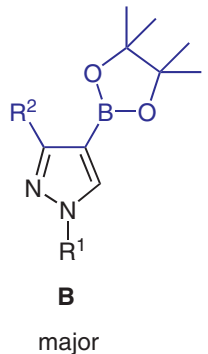

major

$10 \% \mathrm{PdCl}_{2}$ (dppf) $\mathrm{R}^{1}=\mathrm{Ph}, 4-\mathrm{MeOC}_{6} \mathrm{H}_{4}$ $\mathrm{K}_{3} \mathrm{PO}_{4}, 1,4$-dioxane

$85^{\circ} \mathrm{C}, 16 \mathrm{~h}$ 4- $\mathrm{ClC}_{6} \mathrm{H}_{4} \mathrm{Br}$ $-\mathrm{O}_{2} \mathrm{NC}_{6} \mathrm{H}_{4}$ $\mathrm{R}^{2}=\mathrm{Ph}$

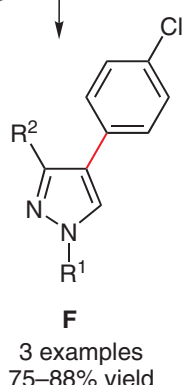

Significance: Reported is a regiospecific synthesis of pyrazole boronic esters from alkynylboronates and $\mathrm{N}$-alkyl or -aryl sydnones by cycloaddition-retro-cycloaddition reaction. The regiochemistry of the decarboxylative [2+3] cycloaddition is governed by the $\mathrm{R}^{2}$ group of the alkynylboronate; thus pyrazole B predominates when $\mathrm{R}^{2}=$ aryl, alkyl, TMS while $\mathbf{C}$ is the major product for terminal alkyne. As expected, electron-rich sydnones A were found to be slow-reacting (2224 h) while more electron-deficient sydnones $\mathbf{A}$ showed significantly faster reactions (2-4 h). The cycloaddition is highly effective for sydnones $\mathbf{D}$ affording fully substituted pyrazoles $\mathbf{E}$ with complete regioselectivity. To complete the presumed reason for this study, pyrazole B was subjected to Suzuki cross-coupling conditions to form $\mathbf{F}$ in good yields.
Comment: Pyrazoles represent a very important class of heterocycles which are found in pharmaceutical and agrochemical substances (C. Lamberth Heterocycles 2007, 71, 1467). Although the present report appears to be the first example of alkynylboronate [2+3] cycloaddition with sydnones for the direct preparation of functionalized pyrazole boronic esters, a similar report of cycloaddition of sydnone with alkynylstannanes and alkynylsilanes has recently appeared (A. M. González-Nogal et al. Tetrahedron 2007, 63, 224). As reported herein, an alternate route rather than a metallation-boronation sequence for the synthesis of frequently unstable heterocyclic boronic acids and their derivatives is welcome. 